\title{
The Influence of a Mandibular Advancement Plate on Polysomnography in Different Grades of Obstructive Sleep Apnea
}

\author{
Antti Raunio ${ }^{1}$, Pauli Mattila ${ }^{1}$, Usko Huuskonen ${ }^{2}$, Kyösti Oikarinen ${ }^{1}$, George K. Sándor ${ }^{1}$ \\ ${ }^{1}$ Department of Oral and Maxillofacial Surgery, Medical Research Center, Oulu University Hospital, Oulu, Finland. \\ ${ }^{2}$ Department of Clinical Neurophysiology, Oulu University Hospital, Oulu, Finland.
}

\author{
Corresponding Author: \\ Antti Raunio \\ Department of Oral and Maxillofacial Surgery \\ Institute of Dentistry, University of Oulu \\ Aapistie 3, 900014, Oulu \\ Finland \\ Phone: +358406737878 \\ Fax: +35885375504 \\ E-mail: antti.raunio@,oulu.fi
}

\begin{abstract}
Objectives: The purpose of this study was to investigate the effect of a mandibular advancement device on different grades of obstructive sleep apnea using a relatively simple test for the apnea-hypopnea index to determine if a mandibular device will be effective.

Material and Methods: A total of 68 patients with obstructive sleep apnea syndrome (OSAS) including, 31 with mild, 23 with moderate and 14 with severe OSAS were treated with a mandibular advancement device (MAD) and monitored with polysomnography.

Results: 25 of the 31 mild, 15 of the 23 moderate and 2 of the 14 severe OSAS patients were cured of their OSAS if a post treatment apnea-hypopnea index of less than 5 is regarded as cured. The odds ratios for success with MAD therapy are 3 for women over men, 14.9 for mild obstructive sleep apnea, 5.42 for moderate obstructive sleep apnea if severe obstructive sleep apnea is assigned an odds ratio of 1 .

Conclusions: The use of the apnea-hypopnea index alone is useful in mild and moderate disease to predict the effectiveness of mandibular advancement device. Treatment with a mandibular advancement device is very effective in treating mild and moderate obstructive sleep apnea. Conservative treatment with a mandibular advancement device can be successful in less severe grades of sleep apnea and may be an alternative for non-surgical patients with severe obstructive sleep apnea intolerant of Continuous Positive Airway Pressure management.
\end{abstract}

Keywords: appliances; obstructive sleep apnea; obstructive sleep apnea syndrome; mandible.

Accepted for publication: 12 March 2015

To cite this article:

Raunio A, Mattila P, Huuskonen U, Oikarinen K, Sándor GK. The Influence of a Mandibular Advancement Plate on Polysomnography in Different Grades of Obstructive Sleep Apnea.

J Oral Maxillofac Res 2015;6(1):e4

URL: http://www.ejomr.org/JOMR/archives/2015/1/e4/v6n1e4.pdf doi: 10.5037/jomr.2015.6104 


\section{INTRODUCTION}

Obstructive sleep apnea syndrome (OSAS) is a common disease that involves at least $4 \%$ of males and $2 \%$ of the female adult population [1]. The diagnosis is based upon a history of subjective experience and polysomnography. The most important anamnestic characteristics are snoring and daytime somnolence [1]. The Epworth Sleepiness Scale describes the patient's own, subjective experiences and is based on a questionnaire and patient interview. Polysomnography, which is carried out using highly specialized equipment, measures several vital functions, the most important of them being the apnea-hypopnea index (AHI) [2] .

In this index a pause of non-breathing greater than 10 seconds or a reduction of breath airflow which is greater than $50 \%$ scores one point. Points are counted on an hourly basis as described in the American Academy of Sleep Medicine Classification [2].

The grade or severity of OSAS according to AHI has been categorized as follows:

- AHI less than 5 - no disease;

- AHI 5 to 15 - mild disease;

- AHI 15 to 30 - moderate disease;

- AHI greater than 30 - severe disease.

The treatment of OSAS is either conservative or surgical. Conservative treatment includes weight loss and the regular use of Continuous Positive Airway Pressure (C-PAP) equipment and a variety of devices that attempt to keep tissues in the anterior part of the upper airway forward. These devices include mandibular advancement devices (MAD), and tongue holding devices $[\underline{3}, \underline{4}]$. C-PAP treatment has been regarded as the "gold standard" in the treatment of OSAS [4]. It has been recommended as an initial treatment in the presence of severe disease $[\underline{5}, \underline{6}]$. Many patients, however, complain that C-PAP is cumbersome and difficult to tolerate [7]. This is especially so among elderly patients in whom C-PAP is regarded as the treatment of choice $[\underline{8}, \underline{9}]$.

Bimaxillary advancement surgery (BMAS) has been shown in a number of studies to be an effective surgical modality to treat OSAS and BMA's effect was comparable to C-PAP treatment $[10,11]$. In our own previously published study we showed that BMAS of the jaws improved OSAS airway parameters [12] and relieved the symptoms of OSAS [13].

A conservative non-surgical technique involving a tooth-borne appliance to advance the mandible without surgery also known as the MAD has already been introduced in the late 1990`s [3]. MAD has been shown, to provide satisfactory treatment of mild to moderate OSAS $[4,14]$. However, there is a limitation in using MAD in completely edentulous patients or those patients with pre-existing temporomandibular joint diseases [15]. MAD has been shown to be especially effective in treating supine dependent sleep apnea [16]. MAD has also been recommended in the treatment of severe OSAS [17-19], especially if the patient is unable to tolerate a C-PAP device [20-22]. Intolerance towards C-PAP equipment occurs in many cases, particularly in obese patients. The weight of OSAS patients is problematic as overweight patients have more severe disease and respond poorly to all forms of treatment $[\underline{14,23]}$.

The purpose of this study was to investigate the effect of a mandibular advancement device on different grades of obstructive sleep apnea using a relatively simple test for the apnea-hypopnea index (which represents the number of apneas or breathless episodes which occur per hour while a subject is sleeping) to determine if a mandibular device will be effective. In addition, the study aimed to observe whether the patient's body mass index, age or gender had an influence on the effect of treatment with a mandibular advancement device.

\section{MATERIAL AND METHODS}

The study material consisted of 68 consecutive OSAS patients (19 females, 49 males) for whom a MAD was prepared. The retrospective study was carried out with the permission of the the Ethical Committee of the Oulu University Hospital using patient registry data. The data were analysed without personal identifying details and the data were treated with the principles of the Helsinki Declaration.

\section{Patient selection}

OSAS patients were referred to the Oral and Maxillofacial Surgery Department (OMFD) of Oulu University Hospital for consultation and treatment mainly by the Pulmonary Division of the Department of Internal Medicine, Oulu University Hospital (PDDIM) or the Otolaryngologic Department (ENT) of the same hospital.

The initial examination of the patients and determination of the OSAS diagnosis was performed by the PDDIM as well as the decision to start the treatment by C-PAP or refer the patients further either to ENT clinic or directly to OMFD. A diagnosis of OSAS was made according to the clinical symptoms and polysomnography results. 
C-PAP treatment was started for all severe cases of OSAS according to the PDDIM protocol. Mild and moderate cases are mostly sent from PDDIM to OMFD for evaluation and the possibility of providing either conservative MAD management or oral and maxillofacial surgical treatment. Patients, who could not tolerate C-PAP, were also referred to OMFD. The decision to use a mandibular advancement plate is made by the OMFD in every case. Some of the revised patients were also evaluated for surgicalorthodontic treatment with bimaxillary surgery.

A total of 68 consecutively referred OSAS patient for whom the MAD treatment was selected, were therefore included in this study. The initiation of the treatment was from July 2005 to December 2013. In all cases the AHI of the patients was 5 or more.

Surgical cases were not included since they were not treated with MAD. Patients were also judged as not suitable for MAD treatment, if they suffered from pre-existing active temporomandibular joint dysfunction or if their dental status or periodontal health precluded them from wearing an oral appliance.
Edentulous patients were also excluded from the study. Patients' age, BMI, general health and such did not influence the selection. None of the initial 68 patients dropped out during the study. Complaints such as minor occlusal changes or temporomandibular joint problems during the treatment did not affect the study course in any case (Figure 1).

In this study the MAD patients were divided into three groups according to their pre-treatment or baseline polysomnography results:

- Mild OSAS;

- Moderate OSAS;

- Severe OSAS.

The gender, AHI, AHI in the supine position, mean ages and BMI of these patients are presented in Table 1.

In this study the "MAD" was a custom-made acrylic monoblock splint which was specifically manufactured for each patient. The device was simple, durable, and well tolerated by the patients. Each device was fabricated by a dental technician at the same dental laboratory (Hammas-Sampo, Oulu, Finland).

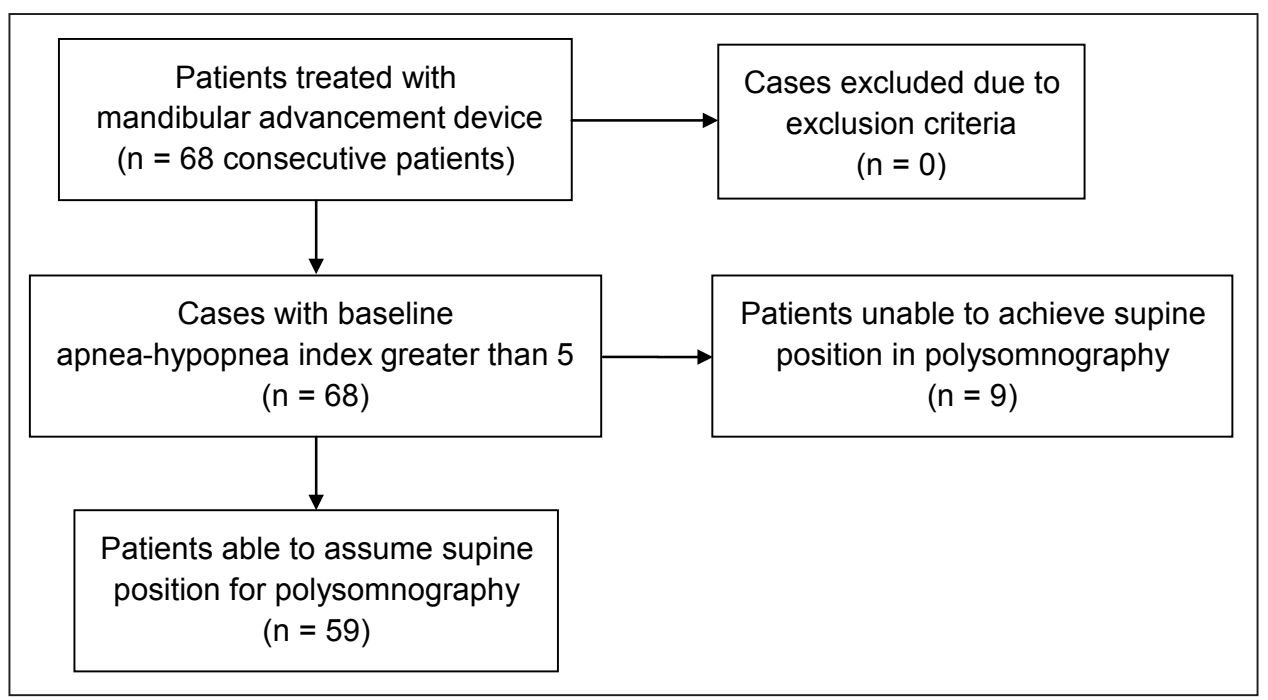

Figure 1. Flow diagram illustrating cases included, excluded and assessed with polysomnography in study.

Table 1. Demographic and clinical characteristics of 68 patients with various severities of obstructive sleep apnea

\begin{tabular}{c|l|c|c|c|c}
\hline \multicolumn{2}{c|}{} & Mild & Moderate & Severe & \multirow{2}{*}{ Total } \\
\cline { 3 - 6 } \multicolumn{2}{c|}{} & $\mathbf{5}$ AHI $\leq \mathbf{1 5}$ & $\mathbf{1 5}<\mathbf{A H I} \leq \mathbf{3 0}$ & $\mathbf{3 0}<\mathbf{A H I} \leq \mathbf{7 9 . 6}$ & \\
\hline \multicolumn{2}{c|}{ Males/Females/N } & $22 / 9 / 31$ & $13 / 10 / 23$ & $14 / 0 / 14$ & $49 / 19 / 68$ \\
\hline \multirow{2}{*}{ AHI } & Mean (SD) & $9.3(2.5)$ & $22.1(4.2)$ & $47.5(15.7)$ & $21.5(16.4)$ \\
\hline \multirow{2}{*}{ AHI supine } & Mean (SD) & $22.5(12.6)$ & $43.3(16.5)$ & $59.7(22.4)$ & $37.9(22.1)$ \\
\cline { 2 - 6 } & Range & $8 ; 65$ & $18 ; 89$ & $33 ; 96$ & $8 ; 96$ \\
\hline \multirow{2}{*}{ Age } & Mean (SD) & $53(8.4)$ & $55.3(8.2)$ & $46.4(14.6)$ & $52.4(5)$ \\
\cline { 2 - 6 } & Range & $35 ; 73$ & $35 ; 68$ & $14 ; 67$ & $14 ; 73$ \\
\hline \multirow{2}{*}{ BMI } & Mean (SD) & $26.9(4.2)$ & $26.8(4.2)$ & $30.9(6.4)$ & $27.4(5)$ \\
\cline { 2 - 5 } & Range & $20 ; 42$ & $20 ; 37$ & $24 ; 47$ & $20 ; 47$ \\
\hline
\end{tabular}

$\mathrm{N}=$ total number of patients; $\mathrm{AHI}=$ apnea-hypopnea index; $\mathrm{SD}=$ standard deviation. 
MAD were made using individually made plaster casts of the teeth, and a bite registration taken using the George Gauge instrument (Dr. Peter T. George, Honolulu, Hawaii, USA) by a hospital dentist. The MAD was designed so that the mandible was in an advanced position of $50 \%$ of its maximum protrusive capacity. The device provided occlusal coverage of all the teeth. A vertical distance between the maxillary and mandibular portions of the device was designed to allow for a breathing opening in the anterior region of the device (Figures 2 and 3).

A standardized polysomnography was performed to determine the pre-treatment diagnosis and for the intra-treatment control after the MAD treatment was initiated. The mean between the onset of MAD treatment and the first control measurement was 0.72 years with a standard deviation of 0.61 and a range of 0.4 to 2.9 years. The influence of this variable period was also studied by the authors. The testing device used for this purpose was a portable Embletta GoldTM (ResMed, Broomfield, Colorado, USA) polysomnography system.

The following criteria were observed during polysomnography: flow pressure (nasal cannula), oral pressure (thermistor), snore (nasal pressure), abdominal movement, thoraracic movement, $\mathrm{SpO}_{2}$ average (oximeter), pulse rate (oximeter), body position, activity, event marker, leg movements. The registered data were analyzed using RemLogicTM PSG Software (Natus Medical Incorporated, San Carlos, California, USA) by the same experienced clinical neurophysiologist for each case.

\section{Statistical analysis}

Descriptive statistics were prepared with means, standard deviations and ranges (M $[\mathrm{SD}],[\mathrm{R}]$ ). Logistic regression analysis was used to determine the factors that possibly affect treatment success. Statistical analyses were performed using SPSS 19.0 computer software (SPSS Inc., Chicago, IL, USA). The significance level was set at $\mathrm{P} \leq 0.05$.

\section{RESULTS}

The patient's pre-treatment mean AHI in the classification groups of mild, moderate and severe, was registered and counted. AHI values in the supine position were also registered in the same manner. The changes in AHI (both mean and supine) were followed in the different severity groups both in ordinal numbers and in percentages according to pre-treatment classification groups (Table 2).

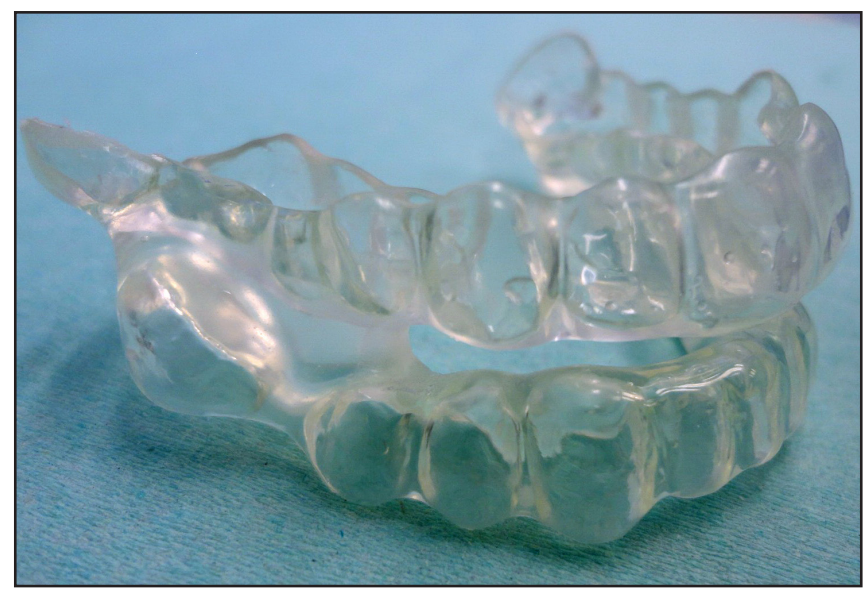

Figure 2. A mandibular advancement device designed with an opening in the anterior region of the device for breathing.

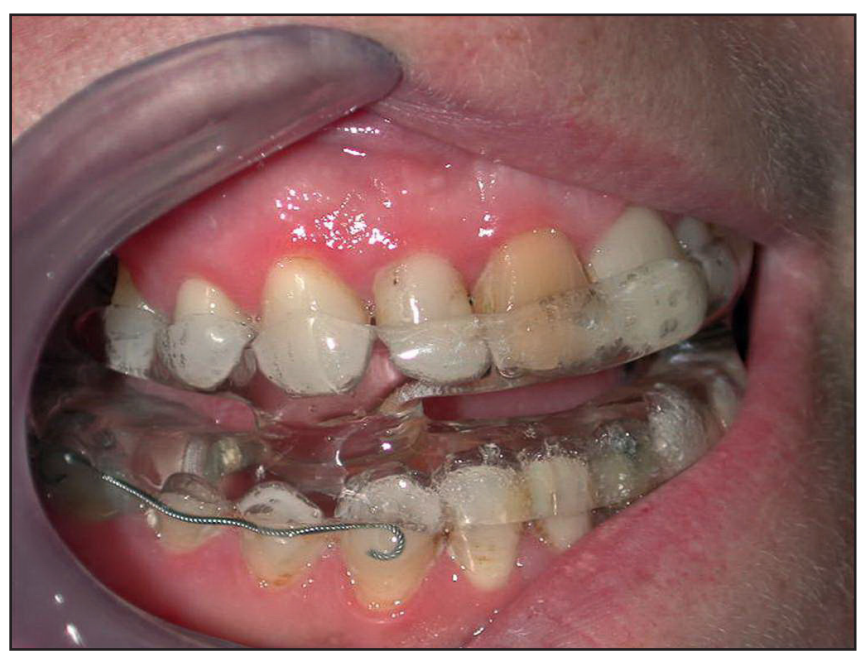

Figure 3. A mandibular advancement device in position in the mouth. Note the protrusion of the mandible set at $50 \%$ of the maximal protrusion.

Those, whose AHI fell below 5 with MAD treatment were considered to be cured (Tables 3 and 4). Since some studies consider responders to experience an improvement of AHI of $50 \%$ or more to be a success, these results are also tabulated to reflect to this concept for an additional comparison (Table 5).

The influence of the patient's age, sex, BMI and the time interval between the onset of the MAD treatment and the control measurement to determine the decrease of AHI were analyzed statistically in Table 6 where a logistic regression model was used to estimate the probability of treatment success. Those patients whose AHI fell to a level below 5 were considered as cured of their OSAS condition. BMI was used as a continuous variable. Gender and the pre-trial degree of sleep apnea were used as predictors. The patients with mild pre-trial sleep apnea symptoms were predicted to have odds of healing as $14.92(\mathrm{P}=0.0004)$ times the odds of healing in the group of patients with severe pre-trial symptoms. 
Table 2. Post-treatment apnea-hypopnea index (AHI) results of 68 patients with various severities of obstructive sleep apnea treated with a mandibular advancement device

\begin{tabular}{|c|c|c|c|c|c|}
\hline & Mild & Moderate & Severe & \multirow{2}{*}{ Total } \\
\hline & & $5<\mathrm{AHI} \leq 15$ & $15<\mathrm{AHI} \leq 30$ & $30<\mathrm{AHI} \leq 79.6$ & \\
\hline \multirow{2}{*}{ AHI control } & Mean (SD) & $3.1(3.5)$ & $4.5(4)$ & $26.8(24.3)$ & $8.5(14.6)$ \\
\hline & Range & $0 ; 16$ & $0 ; 16$ & $0 ; 82$ & $0 ; 82^{\mathrm{a}}$ \\
\hline \multirow{2}{*}{ AHI difference \% } & Mean (SD) & $64.4(37.8)$ & $79(20.3)$ & $47.6(39.8)$ & $65.9(34.5)$ \\
\hline & Range & $-36 ; 99$ & 9; 99 & $-13 ; 100$ & $-36 ; 100^{a}$ \\
\hline \multirow{2}{*}{ AHI supine control } & Mean (SD) & $6(7.5)$ & $12.5(11.4)$ & $33.2(26.6)$ & $13.1(17)$ \\
\hline & Range & $0 ; 34$ & $1 ; 40$ & $4 ; 78$ & $0 ; 78^{\mathrm{b}}$ \\
\hline \multirow{2}{*}{ AHI supine difference \% } & Mean (SD) & $69.6(27.7)$ & $71.1(29.6)$ & $46(39.8)$ & $65.9(31.1)$ \\
\hline & Range & $18 ; 98$ & $-24 ; 97$ & $-23 ; 93$ & $-24 ; 98^{\mathrm{b}}$ \\
\hline
\end{tabular}

${ }^{\mathrm{a}} \mathrm{N}=68$ represents 68 patients in this study having $\mathrm{AHI}>5$.

${ }^{b} \mathrm{~N}=59$ represents the 59 patients that were capable of tolerating $\mathrm{AHI}$ measurements in the supine position.

$\mathrm{SD}=$ standard deviation.

Table 3. Improvement in post-treatment obstructive sleep apnea severity classification

\begin{tabular}{c|c|c|c|c}
\hline \multicolumn{1}{c|}{ AHI initial } & Follow-up AHI $<\mathbf{5}$ & Follow-up AHI & Follow-up AHI & Follow-up AHI \\
\hline Baseline & "Cured" & Mild & Moderate & Severe \\
\hline Mild $(\mathrm{n}=31)$ & 25 & 5 & 1 & 0 \\
\hline Moderate $(\mathrm{n}=23)$ & 15 & 17 & 1 & 0 \\
\hline Severe $(\mathrm{n}=14)$ & 2 & 4 & 3 & 5 \\
\hline
\end{tabular}

$\mathrm{n}=$ total number of patients with either mild, moderate or severe grades of obstructive sleep apnea.

There was an improvement in 68 patients with different grades of obstructive sleep apnea. Patients with post-treatment apnea-hypopnea index (AHI) scores of less than 5 were considered to be "cured".

Table 4. Apnea-hypopnea index (AHI) in supine position in 59 of the 68 patients who were able to assume a supine position during polysomnography for AHI determination

\begin{tabular}{l|c|c|c|c}
\hline \multirow{2}{*}{$\begin{array}{c}\text { AHI initial supine } \\
\text { position }\end{array}$} & \multicolumn{4}{|c}{ Follow-up supine AHI } \\
\cline { 2 - 5 } "Cured" & Mild & Moderate & Severe \\
\hline Mild $(\mathrm{n}=13)$ & 8 & 5 & 0 & 0 \\
\hline Moderate $(\mathrm{n}=14)$ & 12 & 1 & 1 & 0 \\
\hline Severe $(\mathrm{n}=32)$ & 6 & 11 & 7 & 8 \\
\hline
\end{tabular}

$\mathrm{n}=$ total number of patients with either mild, moderate or severe grades of obstructive sleep apnea.

Table 5. Patients with improvement of their apnea-hypopnea index (AHI) scores by at least $50 \%$ used as the criteria to assess responder patients

\begin{tabular}{c|c|c|c|c|c|c}
\hline \multirow{2}{*}{ Improvement } & \multicolumn{3}{|c|}{ AHI (Initial) } & \multicolumn{3}{c}{ AHI supine position (Initial) } \\
\cline { 2 - 7 } & Mild & Moderate & Severe & Mild & Moderate & Severe \\
\hline$<50 \%$ & 9 & 1 & 7 & 4 & 1 & 10 \\
\hline$>50 \%$ & 22 & 22 & 7 & 9 & 13 & 22 \\
\hline
\end{tabular}

The odds for healing in patients with moderate pretrial symptoms were predicted to be $5.42(\mathrm{P}=0.077)$ times the odds of healing for the severe group. An increase in the BMI index of one unit was expected to cause a statistically significant decrease in the odds for healing $(\mathrm{OR}=0.83, \mathrm{P}=0.027)$. No difference $(\mathrm{P}$ $=0.158)$ was observed between females and males.
No statistically significant change in Table 6 was noted when the patient's age $(\mathrm{P}=0.145)$ or time between the start of MAD therapy and the control intra-treatment measurements was added to the model $(\mathrm{P}=0.211)$ or when the BMI index in the model was replaced with predictors such as age or time between the measurements. 
Table 6. Logistic regression model

\begin{tabular}{|c|c|c|c|c|c|}
\hline \multicolumn{2}{|c|}{ Parameter } & \multicolumn{2}{|c|}{$\begin{array}{l}\text { A Routine polysomnography } \\
\qquad(\mathrm{n}=68)\end{array}$} & \multicolumn{2}{|c|}{$\begin{array}{l}\text { B Supine position polysomnography } \\
(\mathrm{n}=59)\end{array}$} \\
\hline & & Odds Ratio & Significance & Odds Ratio & Significance \\
\hline \multirow{2}{*}{ Gender } & Female & 3.01 & 0.158 & 1.07 & 0.928 \\
\hline & Male & 1 & & & \\
\hline \multicolumn{2}{|l|}{ BMI } & 0.83 & 0.027 & 0.98 & 0.800 \\
\hline \multirow{3}{*}{$\begin{array}{l}\text { Pre-trial } \\
\text { sleep apnea } \\
\text { severity }\end{array}$} & Mild & 14.95 & 0.004 & 25.24 & 0.000 \\
\hline & Moderate & 5.42 & 0.077 & 6.46 & 0.017 \\
\hline & Severe & 1 & & & \\
\hline
\end{tabular}

A logistic regression model used to estimate the probability of treatment success. Those subjects whose apnea-hypopnea index fell below 5 were considered to as cured. Body mass index (BMI) was used as a continuous variable. Gender and the pre-trial severity of sleep apnea were used as predictors.

The logistic model for supine AHI in Table 6 column $\mathrm{B}$ gave similar results. In this model the differences between groups mild, moderate and severe was slightly greater and the effect of BMI was not significant $(\mathrm{P}=0.8)$.

\section{DISCUSSION}

The mandibular protrusion was set at $50 \%$ of the maximal protrusion because this amount of advancement has been shown to be effective by other authors [ $[,, \underline{8}]$. While more pronounced mandibular advancement has been shown to be more effective in reducing AHI [ $\underline{8}, \underline{9}]$, the untoward effects are increased with excessive protrusion and compliance is reduced. This $50 \%$ of maximal mandibular protrusion is therefore accepted as a good compromise [7]. According to the results of this study an average fall of $65 \%$ in AHI can be expected with MAD treatment in the OSAS patients in this cohort.

\section{Mild AHI group}

The results of MAD treatment in the mild group were positive with 25 out of 31 patients achieving an AHI reduction to the cured levels. Their odds ratio was 14.95. MAD treatment also improved the condition of 5 of the other 6 remaining mild AHI patients, although they were not cured. For an unknown reason, one female patient's AHI classification deteriorated as it rose up to "moderate" disease.

\section{Moderate AHI group}

In the case of moderate OSAS 15 out of 23 patients were cured (with an odds ratio of 5.42), 7 others experienced an AHI reduction which allowed them to be reclassified to the mild group. Only 1 patient remained in the moderate group.
These results of this study are in agreement with many previous studies $[\underline{3}, \underline{4}, \underline{14}-19, \underline{24}, \underline{25}]$. Mild and moderate OSAS responded effectively to MAD treatment. In fact MAD treatment cured the majority of the patients and improved the AHI of many of those who were not cured. In this material 46 patients of the mild and moderate groups (totalling 58 patients) became cured and the remaining 12 patient's conditions were significantly improved.

The percentage changes in these two groups were very similar. The mean change of AHI was greatest in the moderate group being $79.6 \%$. This compared favourably with the mild group which was $64.4 \%$. The mean residual AHI in these groups was below 5 (being 3.1 and 4.5). The odds ratio showed that a patient with mild OSAS has 15 times and one with moderate has a 5.4 times better chance of being cured with a MAD than a patient with severe disease. The results also showed that AHI can be used to determine the effectiveness of a mandibular positioning device in mild to moderate AHI.

\section{Severe AHI group}

The results in the severe group are more complicated to interpret. The mean numerical decrease of AHI in this severe group was a mean of 20.8 , with remaining residual AHI of 26.7. The mean percentage decrease was $47.6 \%$. Two patients out of 14 patients became cured, 3 patients improved from severe to mild and 4 patients improved from severe to the moderate group, while 5 patients remained in severe group. The mean percentage decrease in AHI was less than in the groups with initially moderate or mild OSAS. This could be, at least partly, explained by a higher mean BMI in this severe patient group. The results show that MAD had a less positive effect on patients with $\mathrm{BMI}>30$. On the other hand some of the patients in the severe group had a considerable decrease of AHI. 
Such decreases have been shown in previous studies $[\underline{3}, \underline{6}]$. The results of this study show the same phenomenon, that people with high supine AHI and lower mean AHI get an especially good response from MAD.

\section{Supine AHI group}

When supine AHI values are considered and the patients are divided in groups (Table 4) then there were 13 patients in the mild group, 14 in the moderate group and 32 in the severe group. From the 13 mild supine patients 8 were cured and 5 remained at their initial AHI severity grouping. Patients with higher supine position classification for example moderate and severe showed a favourable trend (Table 4). This is also supported by the previous observations of Marklund et al. $[\underline{3}, \underline{6}]$.

\section{Patient age}

The patients in severe group (46.4 years) were younger than the patients in the mild (53 years) and moderate (55.3 years) groups. It might be worthwhile to note that the patients with severe disease were heavier and younger than the average of the entire study group. The data of this study indicates that age did not have a significant influence on the outcome of MAD treatment.

\section{Body mass index}

In patients with mild or moderate OSAS the BMI was near normal (26.9 and 26.8 respectively) while the patients with severe OSAS were considerably heavier (mean BMI 30.9). The BMI was considerably higher in the severe group than in the other groups. Also the decrease in AHI with MAD treatment was worse in patients with high BMI values. This is especially true in obese men.

The BMI had a significant influence on the effect of MAD (Table 3). Heavier patients performed worse with MAD treatment than the others (Table 3). This is in also agreement with previous reports by Marklund $[\underline{3}, \underline{6}]$. This does not mean, however, that the treatment of obese patients with MAD would be unjustified.

\section{Gender influences}

Gender did not have any significant influence on the effect of MAD treatment. Patients with severe OSAS were all men and their BMI was significantly higher than the rest of the study material. In this study the mean decrease in AHI was 65.2 with 76.2 in females and 52.2 in males. While the females had a better response, it was not statistically significant.

\section{Responder patients versus cured patients}

Patients with OSAS were considered cured if their AHI scores dropped to less than 5 [3] and these cases are presented in Tables 3 and 4. Responders were defined as patients with a reduction in AHI following MAD treatment of greater than or equal to $50 \%$ compared to pre-treatment AHI scores. Nonresponders were defined as patients with a reduction in AHI of less than $50 \%$ [4]. The results in Table 5 show that an improvement of more than $50 \%$ can be expected in the majority of OSAS cases treated with MAD, particularly in the mild and moderate groups where there is an improvement of $75 \%$. This improvement is comparable to the $68.8 \%$ reported by Dieltjens et al. [4]. In the severe group the improvement is just $50 \%$. The same pattern follows in the supine position where there is a $74 \%$ improvement in the mild and moderate groups. MAD treatment effectively reduced AHI in mild and moderate OSAS groups. The results of treating severe OSAS with MAD appear less predictable. In some severe OSAS cases MAD had a beneficial effect, while in some others the effect was insufficient.

\section{CONCLUSIONS}

Treatment with a mandibular advancement device is very effective in treating mild and moderate obstructive sleep apnea and this is supported by numerous previous studies. One unique feature of this study is that with the simple test of the apneahypopnea index the authors were able to determine if the use of a mandibular repositioning device will be effective, thus saving time and costs associated with further more complicated diagnostic tests. Treating severe obstructive sleep apnea with therapy using a mandibular advancement device is more controversial. The expectation for full recovery is not very high with severe obstructive sleep apnea patients, but considerable improvement in the apnea-hypopnea index levels may occur. This favours treatment with a mandibular advancement device in many cases. A control polysomnography to assess treatment outcome is necessary especially in severe obstructive sleep apnea cases. Further treatment is required if therapy with a mandibular advancement device does not produce satisfactory outcomes. If Continuous-Positive Airway Pressure, which is another alternative, is not tolerated by the patient, 
then very limited conservative treatment modalities remain. It is equally worthwhile to treat both females and males with a mandibular advancement device disregarding the age. Control of weight remains essential.

In this study patients with severe obstructive sleep apnea had the highest body mass index values. The results of the study also show that treatment with a mandibular advancement device is less effective in patients with higher body mass index values (BMI $>30$ ). This does not mean that treating overweight patients with a mandibular advancement device would be contraindicated.

\section{ACKNOWLEDGMENTS AND DISCLOSURE STATEMENTS}

The authors wish to thank Mr. Ahti Niinimaa for his help with the statistical analysis of this study. The authors have no conflicts of interest to disclose.

\section{REFERENCES}

1. Young T, Palta M, Dempsey J, Skatrud J, Weber S, Badr S. The occurrence of sleep-disordered breathing among middleaged adults. N Engl J Med. 1993 Apr 29;328(17):1230-5. [Medline: 8464434] [doi: 10.1056/NEJM199304293281704]

2. Ruehland WR, Rochford PD, O’Donoghue FJ, Pierce RJ, Singh P, Thornton AT. The new AASM criteria for scoring hypopneas: Impact on the apnea hypopnea index. Sleep. 2009 Feb;32(2):150-7. [Medline: 19238801] [PMC free article: 2635578]

3. Marklund M, Franklin KA, Sahlin C, Lundgren R. The effect of a mandibular advancement device on apneas and sleep in patients with obstructive sleep apnea. Chest. 1998 Mar;113(3):707-13. [Medline: 9515847] [doi: 10.1378/chest.113.3.707]

4. Dieltjens M, Vanderveken OM, Hamans E, Verbraecken JA, Wouters K, Willemen M, De Backer WA, Van de Heyning PH, Braem MJ. Treatment of obstructive sleep apnea using a custom-made titratable duobloc oral appliance: A prospective clinical study. Sleep Breath. 2013 May;17(2):565-72. [Medline: 22581485] [PMC free article: 3655219$]$ [doi: $10.1007 / \mathrm{s} 11325-012-0721-3]$

5. Schmidt-Nowara W, Lowe A, Wiegand L, Cartwright R, Perez-Guerra F, Menn S. Oral appliances for the treatment of snoring and obstructive sleep apnea: A review. Sleep. 1995 Jul;18(6):501-10. [Medline: 7481421]

6. Marklund M, Netzer NC. Report from the first conference of the european dental sleep medicine academy. Sleep Breath. 2005 Mar;9(1):41-2. [Medline: 15785921] [doi: 10.1007/s11325-005-0007-0]

7. Quinnell TG, Clutterbuck-James AL. Alternatives to continuous positive airway pressure 2: Mandibular advancement devices compared. Curr Opin Pulm Med. 2014 Nov;20(6):595-600. [Medline: 25221854] [doi: 10.1097/MCP.0000000000000096]

8. Fleury B, Cohen-Levy J, Lacassagne L, Buchet I, Geraads A, Pegliasco H, Gagnadoux F. Treatment of obstructive sleep apnea syndrome using a mandibular advancement device. Rev Mal Respir. 2010 Oct;27 Suppl 3:S146-56. [Medline: 21129623] [doi: 10.1016/S0761-8425(10)70020-6]

9. Gagnadoux F, Fleury B, Vielle B, Petelle B, Meslier N, N'Guyen XL, Trzepizur W, Racineux JL. Titrated mandibular advancement versus positive airway pressure for sleep apnoea. Eur Respir J. 2009 Oct;34(4):914-20. [Medline: 19324954] [doi: 10.1183/09031936.00148208]

10. Conradt R, Hochban W, Heitmann J, Brandenburg U, Cassel W, Penzel T, Peter JH. Sleep fragmentation and daytime vigilance in patients with OSA treated by surgical maxillomandibular advancement compared to CPAP therapy. J Sleep Res. 1998 Sep;7(3):217-23. [Medline: 9785277] [doi: 10.1046/j.1365-2869.1998.00116.x]

11. Conradt R, Hochban W, Brandenburg U, Heitmann J, Peter JH. Long-term follow-up after surgical treatment of obstructive sleep apnoea by maxillomandibular advancement. Eur Respir J. 1997 Jan;10(1):123-8. [Medline: 9032503] [doi: 10.1183/09031936.97.10010123]

12. Meisami T, Musa M, Keller MA, Cooper R, Clokie CM, Sàndor GK. Magnetic resonance imaging assessment of airway status after orthognathic surgery. Oral Surg Oral Med Oral Pathol Oral Radiol Endod. 2007 Apr;103(4):458-63. [Medline: 17395062] [doi: 10.1016/j.tripleo.2006.07.006]

13. Raunio A, Rauhala E, Kiviharju M, Lehmijoki O, Sándor GK, Oikarinen K. Bimaxillary advancement as the initial treatment of obstructive sleep apnea: Five years follow-up of the Pori experience. J Oral Maxillofac Res. 2012 Apr 1;3(1):e5. [Medline: 24422007] [doi: 10.5037/jomr.2012.3105]

14. Marklund M, Stenlund H, Franklin KA. Mandibular advancement devices in 630 men and women with obstructive sleep apnea and snoring: Tolerability and predictors of treatment success. Chest. 2004 Apr;125(4):1270-8. [Medline: 15078734 ] [doi: $10.1378 /$ chest.125.4.1270]

15. Näpänkangas R, Raunio A, Sipilä K, Raustia A. Effect of mandibular advancement device therapy on the signs and symptoms of temporomandibular joint disorders. J Oral Maxillofac Res 2013 Jan; 3(4):e5. [Medline: 24422023] [PMC free article: 3886094$]$ 
16. Marklund M, Persson M, Franklin KA. Treatment success with a mandibular advancement device is related to supinedependent sleep apnea. Chest. 1998 Dec;114(6):1630-5. [Medline: 9872199] [doi: 10.1378/chest.114.6.1630]

17. Walker-Engstrom ML, Ringqvist I, Vestling O, Wilhelmsson B, Tegelberg A. A prospective randomized study comparing two different degrees of mandibular advancement with a dental appliance in treatment of severe obstructive sleep apnea. Sleep Breath. 2003 Sep;7(3):119-30. [Medline: 14569523] [doi: 10.1007/s11325-003-0119-3]

18. Cohen R. Obstructive sleep apnea: Oral appliance therapy and severity of condition. Oral Surg Oral Med Oral Pathol Oral Radiol Endod. 1998 Apr;85(4):388-92. [Medline: 9574946] [doi: 10.1016/S1079-2104(98)90062-2]

19. White DP, Shafazand S. Mandibular advancement device vs CPAP in the treatment of obstructive sleep apnea: Are they equally effective in short term health outcomes? J Clin Sleep Med. 2013 Sep;9(9):971-2. [Medline: 23997711] [doi: $10.5664 /$ jesm.3008]

20. Lee CH, Mo JH, Choi IJ, Lee HJ, Seo BS, Kim DY, Yun PY, Yoon IY, Won Lee H, Kim JW. The mandibular advancement device and patient selection in the treatment of obstructive sleep apnea. Arch Otolaryngol Head Neck Surg. 2009 May;135(5):439-44. [Medline: 19451462] [doi: 10.1001/archoto.2009.31]

21. Jalbert F, Lacassagne L, Bessard J, Dekeister C, Paoli JR, Tiberge M. Oral appliances or maxillomandibular advancement osteotomy for severe obstructive sleep apnoea in patients refusing CPAP. Rev Stomatol Chir Maxillofac. 2012 Feb;113(1):19-26. [Medline: 22244739] [doi: 10.1016/j.stomax.2011.11.005]

22. Marchese-Ragona R, Manfredini D, Mion M, Vianello A, Staffieri A, Guarda-Nardini L. Oral appliances for the treatment of obstructive sleep apnea in patients with low C-PAP compliance: A long-term case series. Cranio. 2014 Oct;32(4):254-9. [Medline: 25252763] [doi: 10.1179/2151090314Y.0000000003]

23. Pahkala R, Seppa J, Ikonen A, Smirnov G, Tuomilehto H. The impact of pharyngeal fat tissue on the pathogenesis of obstructive sleep apnea. Sleep Breath. 2014 May;18(2):275-82. [Medline: 23877124] [doi: 10.1007/s11325-013-0878-4]

24. Dieltjens M, Vanderveken OM, Heyning PH, Braem MJ. Current opinions and clinical practice in the titration of oral appliances in the treatment of sleep-disordered breathing. Sleep Med Rev. 2012 Apr;16(2):177-85. [Medline: 22033170] [doi: 10.1016/j.smrv.2011.06.002]

25. Cohen R. Obstructive sleep apnea: Oral appliance therapy and severity of condition. Oral Surg Oral Med Oral Pathol Oral Radiol Endod. 1998 Apr;85(4):388-92. [Medline: 9574946] [doi: 10.1016/S1079-2104(98)90062-2]

\section{To cite this article:}

Raunio A, Mattila P, Huuskonen U, Oikarinen K, Sándor GK. The Influence of a Mandibular Advancement Plate on Polysomnography in Different Grades of Obstructive Sleep Apnea.

J Oral Maxillofac Res 2015;6(1):e4

URL: http://www.ejomr.org/JOMR/archives/2015/1/e4/v6n1e4.pdf

doi: $10.5037 /$ jomr.2015.6104

Copyright (C) Raunio A, Mattila P, Huuskonen U, Oikarinen K, Sándor GK. Published in the JOURNAL OF ORAL \& MAXILLOFACIAL RESEARCH (http://www.ejomr.org), 31 March 2015.

This is an open-access article, first published in the JOURNAL OF ORAL \& MAXILLOFACIAL RESEARCH, distributed under the terms of the Creative Commons Attribution-Noncommercial-No Derivative Works 3.0 Unported License, which permits unrestricted non-commercial use, distribution, and reproduction in any medium, provided the original work and is properly cited. The copyright, license information and link to the original publication on (http://www.ejomr.org) must be included. 